\title{
Produção de conhecimento pelas mídias sociais: um olhar retrospectivo da polarização política dos fenômenos do Brexit e do impeachment presidencial de 2016
}

Knowledge production by social media: a retrospective look at the political polarization of the Brexit phenomena and the Presidential impeachment of 2016

\author{
Simone Cristina Dufloth* \\ Cristina Camila Teles Saldanha**
}

\section{RESUMO}

O artigo aborda o uso de mídias sociais na criação de sentido voltada à produção de conhecimento a partir da polarização política no Reino Unido e no Brasil. Foi analisado $o$ teor das manifestações apresentadas em hashtags do Twitter sobre o Brexit e o impeachment de 2016. Nas mídias sociais, o estudo evidencia comportamentos polarizados, porém distintos: no Reino Unido destacam-se os efeitos da decisão e, no Brasil, o posicionamento ideológico envolvido na questão. Conclui-se que nesses contextos de polarização, as mídias sociais intensificam o debate e a diversidade de opiniões, favoráveis ao processo democrático e à produção de conhecimento estimulada pela ambiguidade.

Palavras-chave: Mídias Sociais Digitais; Polarização Política; Produção de Conhecimento; Brexit; Impeachment 2016.

\begin{abstract}
The article discusses the use of social media in the creation of sense directed to knowledge production based on political polarization in the United Kingdom and Brazil. It analyzed the content of the manifestations presented in Twitter hashtags on the Brexit and the impeachment of 2016. In the social media, the study evidences polarized, but distinct behaviors: in the United Kingdom the effects of the decision stand out and, in Brazil, the positioning involved in the issue. It is concluded that in these contexts of polarization, social media intensify the debate and diversity of opinions favorable to the democratic process and the production of knowledge stimulated by ambiguity.
\end{abstract}

Keywords: Digital Social Media. Political Polarization; Knowledge Production; Brexit; 2016; Impeachment.

\footnotetext{
* Doutora em Ciência da Informação pela Universidade Federal de Minas Gerais (UFMG). Professora do Programa de Mestrado em Administração Pública da Escola de Governo Professor Paulo Neves de Carvalho da Fundação João Pinheiro. Endereço: Alameda das Acácias, nº 70, São Luiz/Pampulha, Cep: 31.275-150. Belo Horizonte, MG. Telefone: (31) 34489569. E-mail: simone.dufloth@fjp.mg.gov.br.

** Mestre em Administração Pública pela Escola de Governo Professor Paulo Neves de Carvalho da Fundação João Pinheiro. Endereço: Alameda das Acácias, nº 70, São Luiz/Pampulha, Cep: 31.275-150. Belo Horizonte, MG. Telefone: (31) 34489569. E-mail: cristina.c.t.saldanha@gmail.com.
} 


\section{INTRODUÇÃO}

Este artigo desenvolve reflexões sobre a criação de sentido, a produção de conhecimento e a tomada de decisão a partir das manifestações de cidadãos postadas por meio de mídias sociais em contextos marcados por questões de polarização política. A polarização política se faz em virtude de divergências entre ideias, objetivos e perspectivas, que levam a posicionamentos antagônicos ou díspares acerca de contextos decisórios ou de iminentes mudanças. Nessa conjuntura, as pessoas assumem diferentes comportamentos que se refletem nas manifestações apresentadas aos grupos sociais que participam. Esse contexto de ambiguidade configura um cenário de desconstrução e reconstrução de significados que levam a intensos debates e estimulam a produção de novos conhecimentos.

As mídias sociais digitais, que se expandiram nos últimos anos e se desenvolveram enquanto uma nova forma de comunicação e interação social, contribuíram para a criação de arenas de debates de grande alcance. Além disso, propiciaram a construção de memórias históricas nos processos de criação de sentido e produção de conhecimento, a partir dos acervos digitais resultantes do armazenamento de manifestações e elocuções, de toda a ordem, efetuados voluntariamente por seus participantes.

Essas memórias, atreladas às análises dos fenômenos a elas relacionados, trazem evidências da evolução do pensamento e das reações de seus participantes, de forma que refletem o processo de criação de sentido e de produção de conhecimento coletivo, e que contribuem para uma melhor compreensão dos fenômenos estudados. Entre as evidências que os acervos digitais propiciam, as mídias sociais digitais oferecem para o presente estudo a análise do comportamento político de cidadãos britânicos e brasileiros, considerando-se possíveis influências culturais ou contextuais que possam refletir nos diferentes posicionamentos. Nos casos estudados do Brexit e do impeachment em 2016, os posicionamentos dicotômicos dos cidadãos britânicos e brasileiros pela rede social Twitter evidenciaram um momento histórico cujas repercussões culminaram em decisões que podem ter influenciado nos resultados das eleições de 2018 no Brasil e no atual imbróglio em que se encontra o processo de saída do Reino Unido da União Europeia.

As informações acerca da polarização política que envolveram esses fenômenos representam um "retrato" dos novos tempos em que a história passa a ser "escrita" também virtualmente, com a disseminação de informações cada vez mais veloz, o que remete à importância das humanidades digitais para a análise desses dois fenômenos. O presente estudo das mídias sociais digitais optou por analisar o Twitter, que se diferencia das demais mídias sociais pelo formato de suas publicações e cujo texto se restringe a um pequeno número de caracteres. No ano de 2016, esse número se restringia a 140 caracteres (PENTEADO; GUERBALI, 2016). O objetivo desta análise foi buscar peculiaridades em relação ao comportamento político de cidadãos britânicos e brasileiros no que se refere a questões polêmicas e conflituosas que afetaram seus respectivos países, além de refletir sobre o uso das mídias sociais digitais, especificamente do Twitter, no processo de criação de sentido e de produção de conhecimento, que podem ter influenciado decisões em face dos posicionamentos difundidos.

O Twitter, dentro de sua configuração restritiva de manifestação, apesar de não representar efetivamente a participação dos cidadãos, serve como um bom norteador da opinião pública mediante assuntos políticos e como um instrumento de medição dos interesses e influências da sociedade no processo de tomada de 
decisão. A pesquisa realizada com base no estudo dos casos do impeachment da presidenta Dilma Rousseff e da saída do Reino Unido do bloco da União Europeia (UE), informalmente denominado de Brexit, analisou as manifestações da opinião pública por meio das hashtags em perspectiva comparada dos dois fenômenos políticos que marcaram o ano de 2016 e repercutiram mundialmente devido à polarização das manifestações. A técnica de pesquisa utilizada foi a netnografia, por meio da observação distanciada de postagens do Twitter em que foram rastreadas hashtags no filtro de busca avançada dessa mídia social. A seleção de hashtags foi realizada pela identificação da polaridade política nos dois fenômenos: \#foradilma versus \#nãovaitergolpe para o impeachment e \#leaveeu versus \#remaineu para o Brexit. Como ambos os fenômenos são fatos históricos, dentro da conjuntura temporal de mídias sociais que avançam vertiginosamente, as buscas pelas hashtags foram filtradas em datas específicas: no impeachment presidencial, a data escolhida foi 17 de abril de 2016 (votação na Câmara dos Deputados) e o dia posterior; e na saída do Reino Unido do bloco europeu, o período corresponde a 23 e 24 de junho de 2016, sendo aquele o dia do referendo sobre o Brexit. Outras técnicas de pesquisa adotadas também abrangeram dados secundários de outros trabalhos - o relatório produzido por Siegel (2016) sobre o Brexit e os estudos de Penteado e Guerbali (2016) e de Malini et al. (2017) acerca do impeachment serão um auxílio para a análise.

\section{O PAPEL DAS MÍDIAS SOCIAIS DIGITAIS NA CRIAÇÃO DE SENTIDO E NA PRODUÇÃO DE CONHECIMENTO COLETIVO PARA A CONSTRUÇÃO DO COMPORTAMENTO POLÍTICO}

As mídias sociais digitais se situam dentro da sociedade atual como parte integrante e essencial do mundo digital. A sociedade do século XXI, configurada no contexto das tecnologias da informação e comunicação (TICS), reveste-se de instrumentos cada vez mais interativos e de integração, evidenciando contextos sociais cada vez mais conectados e sensíveis a mudanças e transformações, que se propagam rapidamente com efeitos e repercussões muitas vezes incomensuráveis. Nesse cenário intrigante, efeitos da atuação das pessoas nas mídias sociais digitais podem ampliar a propagação de novas ideias e ambiguidades que estimulam a produção de conhecimento coletivo, especificamente dentro da perspectiva do comportamento político e da consciência cidadã. Ao mesmo tempo, o mundo digital oferece também novas ferramentas que podem influenciar um novo contexto de produção de conhecimento.

\section{Mídias sociais na criação de sentido e na produção de conhecimento}

Segundo Choo (2003), embora tratados como processos independentes, a criação de sentido, a produção de conhecimento e a tomada de decisão são processos interligados. O conceito de sensemaking, ou seja, criação de sentido, reflete a necessidade de se dar sentido a situações de mudança ou ruptura. Para Weick (1995), o sensemaking envolve a construção da identidade a partir das interações sociais; a consideração de circunstâncias ou situações anteriores; ambientes mutáveis e em transformação; além de um contexto social com significados compartilhados, e um processo contínuo de construção direcionado para criar sentido a partir da identificação de pistas impulsionadas pela plausibilidade e coerência, em vez da precisão. O sensemaking reflete a reorganização de ideias e conceitos a partir da 
necessidade de se reduzir incertezas e minimizar ambiguidades estabelecidas em situações de mudanças ou de transformação.

O contexto das mídias sociais digitais parece colaborar com o processo de criação de sentido, principalmente quando tais mídias estão sendo utilizadas para propagar manifestações sobre questões ambíguas e emblemáticas, como nos casos do Brexit e do impeachment de 2016. Essas duas situações enquadram-se como exemplos de contextos de rupturas, para os quais os atores envolvidos se encontram em processos de redefinição de significados, o que impacta nas relações sociais e na construção da identidade dos indivíduos.

Por outro lado, segundo Choo (2003), a produção de conhecimento se estabelece de forma interligada ao processo de criação de sentido, uma vez que é orientada por este. Para Nonaka e Takeuchi (1997), na produção de conhecimento a ambiguidade se faz necessária, uma vez que pode servir para a construção de novos conhecimentos, oriundos do caos criativo, e que contribuem para uma nova forma de se pensar.

Nesse sentido, a produção de conhecimento poderia ser estimulada no contexto das mídias sociais digitais, tanto no que tange à sua dinâmica, que intensifica e expande debates, quanto na recuperação e na análise do seu acervo digital dos registros de manifestações realizadas em períodos históricos, e que trazem elementos importantes para a construção do conhecimento. Dentro dessa última perspectiva, ao se destacar as transformações vivenciadas pelas tarefas dos historiadores com a "virada digital" em termos de "história digital" ou "história por meios digitais", Noiret (2015) apoia-se na concepção de Dacos (2011) sobre as humanidades digitais relativas à ligação entre o conhecimento das ciências humanas e sociais e o mundo digital. Nelas, não há uma negação do passado, mas sim apropriação dos conhecimentos próprios dessas disciplinas, ao mesmo tempo que são mobilizadas as singularidades do mundo virtual. Para Dacos (2011), a escolha do mundo pelo digital modifica e questiona tanto a produção quanto a divulgação dos conhecimentos. Novas fontes surgem então para a produção de conhecimentos nesse meio digital, e a história passa a incorporar "diversas tramas narrativas da web" (NOIRET, 2015, p. 32). Entre essas novas fontes, este estudo inclui as manifestações nas mídias sociais digitais sobre o comportamento político dos cidadãos perante contextos de polarizações políticas.

\section{Mídias sociais para a construção do comportamento político}

O comportamento político se configura a partir de atitudes e discursos que demonstram interesses e influências estabelecidas em prol de questões que afetam grupos sociais ou a sociedade como um todo. Segundo Spinelli (2010, p. 16),

[...] comportamentos políticos são as atividades não formais de indivíduos ou grupos que, mediante o uso do poder de que dispõem, visam intencionalmente influenciar atitudes ou valores e, assim, modificar a distribuição de recursos e vantagens dentro da organização

Atualmente novos instrumentos de comunicação impulsionados pela internet e pelo uso das mídias sociais têm multiplicado os canais de interlocução da sociedade, ao propiciar novos mecanismos de manifestação social e de demonstração de interesses e influências, de forma que contribuem para o comportamento político dos cidadãos. 
Segundo Penteado e Guerbali (2016), as mídias sociais proporcionam um caráter mais interativo, em detrimento de outros meios tradicionais de comunicação, ao se adequarem a uma estrutura de rede. De fato, as contribuições das tecnologias de informação e comunicação, no âmbito das redes sociais e da dinâmica social e política, são inegáveis devido a vários fatores que facilitam a interação multidirecional de seus envolvidos, além da crescente expansão e capilaridade de alcance.

Dentre as plataformas digitais de redes sociais mais utilizadas atualmente, estão o Facebook e o Twitter. Cada mídia social tem uma configuração própria e atende a um público-alvo diversificado (PENTEADO; GUERBALI, 2016). Tais características não implicam que uma plataforma de mídia social possua um formato melhor ou tenha uma qualidade maior em comparação com a outra, mas sim atendem a demandas diferentes.

Isso foi demonstrado durante a campanha presidencial de Barack Obama na eleição americana de 2008. Gomes et al. (2009) constataram a relevância da internet na campanha online de Obama, que utilizou diversos recursos digitais, entre eles as redes sociais como o MySpace, o Facebook, o falecido Orkut, e também outras redes sociais destinadas a nichos específicos, como redes sociais para grupos minoritários nos EUA (grupos raciais, hipânicos, público LGBT, etc.).

Em seu estudo sobre a análise de sentimentos em mídias sociais para mensurar a opinião dos cidadãos acerca da atuação governamental e, consequentemente, da contribuição para a melhoria dos serviços públicos, Oliveira e Bermejo (2017) observaram a opinião dos cidadãos brasileiros nas plataformas Facebook e Twitter quanto à política e à administração pública, vide o combate à corrupção, os problemas do transporte público e os gastos com a Copa do Mundo Fifa 2014. Os autores identificaram que a repercussão desses fatos nas mídias sociais motivou os cidadãos aos protestos nas ruas em 2013, e cujo impacto pode ter influenciado em eventos posteriores que culminaram no impeachment presidencial em 2016.

O avanço vertiginoso das TICs transformou a forma como os indivíduos se interagem na sociedade, inclusive no âmbito político, devido à configuração de um novo ambiente marcado pela multiplicidade de atores que se relacionam. A constituição de um espaço sem fronteiras desenvolvido de forma virtual, não delimitado fisicamente e com maior possibilidade de acesso a todos, resultou na emergência das mídias sociais digitais como uma estrutura de rede de pessoas conectadas a partir de aspectos que lhe são comuns, seja por estabelecerem relacionamentos afetivos ou profissionais, seja por compartilharem ideias e pensamentos.

Em termos de participação cidadã, de acordo com a perspectiva da democracia participacionista, a internet pode ser vista como uma "promessa" de maior participação popular, de autogoverno ou democracia direta, em que haveria uma diminuição dos intermediários como partidos políticos, mídias e burocracia na relação entre a sociedade e o Estado (GOMES, 2010).

Conforme Moises (2008 citado por ARAÚJO et al., 2013), um dos componentes de um regime democrático é a liberdade de expressão e o acesso a formas alternativas de informação, visto que a democracia, mesmo uma democracia digitalizada, envolve participação e contestação pacífica. As mídias sociais digitais apresentam-se como uma nova forma de interlocução entre o governo e os cidadãos, na qual a participação política nesses ambientes virtuais é um indicador da expressão popular e do controle social. No cenário da democracia digital, a interação entre cidadão e governo por via das mídias sociais digitais governamentias ainda é insuficiente no Brasil, limitando-se em grande parte a um canal informativo (FARRANHA et al., 2015). 
Já o Reino Unido é o destaque em termos de e-democracia e e-participação, ocupando o primeiro lugar no ranking na pesquisa sobre e-government da ONU de 2016, distante do Brasil, que está na quinquagésima primeira colocação, tal como mostra a Tabela 1.

Tabela 1 - Comparação entre Brasil e Reino Unido pelos dados da pesquisa United Nations E-government Survey de 2016

\begin{tabular}{l|l|l|l|l}
\hline $\begin{array}{l}\text { Nome do } \\
\text { País }\end{array}$ & $\begin{array}{l}\text { E-Government } \\
\text { Rank }\end{array}$ & $\begin{array}{l}\text { E-Government } \\
\text { Index }\end{array}$ & $\begin{array}{l}\text { E-Participation } \\
\text { Rank }\end{array}$ & $\begin{array}{l}\text { E-Participation } \\
\text { Index }\end{array}$ \\
\hline $\begin{array}{l}\text { Reino } \\
\text { Unido }\end{array}$ & $1^{\circ}$ & 0.91928 & $1^{\circ}$ & 1.00000 \\
Brasil & $51^{\circ}$ & 0.63769 & $37^{\circ}$ & $0.72881,0$ \\
\hline
\end{tabular}

Fonte: ONU, 2016.

A participação política dos cidadãos através das mídias sociais digitais pode ocorrer pela interação dos usuários com as páginas ou perfis governamentais, ou de forma independente pela própria sociedade, ao se constituírem espaços de debates políticos. O comportamento político dos cidadãos, manifestado pelas mídias sociais digitais em situações de polarização, como nos casos do Brexit e do impeachment de 2016, podem demonstrar aspectos da participação cidadã representativos de possíveis influências culturais e contextuais envolvidas no processo de criação de sentido e de produção de conhecimento.

A participação popular pela manifestação política em redes sociais é apontada em investigações empíricas a partir da formação de nichos de compartilhamento de ideias. No entanto, Penteado e Guerbali (2016), ao analisarem os perfis de usuários no Twitter no período de manifestações pró-impeachment, afirmam que não houve um debate político, pois os usuários se relacionavam em grupos fechados pela afinidade entre suas concepções políticas.

Em contrapartida ao argumento da composição de grupos fechados de usuários, Barberá (2015) investiga como as mídias sociais digitais reduzem a polarização política. $O$ autor analisou as posições ideológicas de indivíduos na Alemanha, na Espanha e nos Estados Unidos em seus perfis na rede social Twitter, argumentando que as plataformas de mídia social aumentam a exposição incidental a mensagens políticas compartilhadas por pares, e que tais sítios eletrônicos facilitam a exposição às mensagens daqueles com quem os indivíduos têm laços sociais fracos, mais susceptíveis de fornecer informação nova. O mesmo autor conclui que as mídias sociais introduzem duas mudanças fundamentais na comunicação entre os indivíduos: "em primeiro lugar, aumenta o volume de informação a que os indivíduos estão expostos; e segundo, afeta o tamanho e a diversidade de suas redes de comunicação pessoal” (BARBERÁ, 2014, p.3, tradução nossa). ${ }^{1}$

Contudo, a maioria dos teóricos argumenta que são construídas redes de comunicação homogêneas cujos indivíduos em interação possuem pensamentos, ideais e opiniões similares, enquanto Barberá (2014) defende o oposto: os indivíduos estão embutidos em redes sociais heterogêneas e estão expostos a diversos

\footnotetext{
1 "first, it increases the volume of information to which individuals are exposed; and second, it affects the size and diversity of their personal communication networks" (BARBERÁ, 2014, p.3)
} 
conteúdos que se tornam moderados ao longo do tempo. Outros estudos destacaram constatações sobre os eventos do Brexit e do impeachment de 2016.

Siegel (2016), em seu relatório sobre a manifestação das motivações dos eleitores do Brexit em plataformas de mídias sociais digitais, verificou aproximadamente 29 milhões de tweets coletados no laboratório do grupo Social Media and Political Participation (SMaPP) da Universidade de Nova York. Inicialmente, nos cinco meses que antecederam ao referendo, ambas as campanhas \#leaveeu e \#remaineu eram populares, mas entre 15 de julho de 2015 e 24 de junho de 2016, dos 25 milhões de tweets referenciados com Brexit que foram tuítados, 3.152.747 tweets continham o termo "leave", e 1.531.404 envolviam o termo "remain". Nos dias que antecederam à votação do referendo, o autor constatou um aumento dramático de tweets relacionados ao Brexit. Os tweets foram em sua maioria de cidadãos comuns, apesar de remeter a algumas figuras midiáticas, como políticos. Siegel (2016) observou também que o percentual majoritário relacionado ao termo "leave" estava ligado à tendência de a nomenclatura Brexit referenciar a saída.

Já o estudo de Malini, Ciarelli e Medeiros (2017) acerca do impeachment de Rousseff também analisou sentimentos de polarização em tweets em dois momentos - no início dos atos pró-impeachment, em 15 de março de 2015, e no dia 27 de agosto de 2016, na consolidação do processo de impeachment que resultou na saída da presidenta. Nos estudos realizados, foram identificados sentimentos predominantes, como antecipação, medo e raiva, em comparação a sentimentos como alegria e surpresa. Tais sentimentos foram predominantes para ambos os lados - favoráveis e contrários -, sendo preciso compreender a raiva e o medo não somente com uma concepção moralista relacionada a uma emoção desmedida e quase irracional, mas também enquanto um comportamento de indignação (MALINI; CIARELLI; MEDEIROS, 2017) que perpassa pela opinião pública sobre os assuntos políticos, principalmente no Brasil com os diversos casos de corrupção. Malini, Ciarelli e Medeiros (2017) apontaram nesse estudo para a necessidade de uma maior articulação entre as ciências sociais e as ciências da computação, para estudar esses fenômenos de comportamentos políticos em mídias sociais e plataformas de rede de relacionamento, área de estudos denominada "ciências sociais computacionais" (MALINI; CIARELLI; MEDEIROS, 2017, p. 338).

Enquanto o trabalho de Malini, Ciarelli e Medeiros (2017) fez uso de técnicas algorítmicas de análise de sentimentos, proporcionando um estudo de natureza mais quantitativa, a presente pesquisa realiza uma análise qualitativa a partir dos estudos de casos comparativos de fenômenos ocorridos, a fim de investigar de forma retrospectiva comportamentos de polarização política em mídias sociais digitais, em contextos políticos, sociais e culturais distintos, e indicar possíveis tendências.

Nesse sentido, esta pesquisa estabeleceu um espaço temporal específico identificado pelo momento de polarização política mais intenso. No caso do impeachment da presidenta Dilma Rousseff, o período escolhido foi a votação na Câmara dos Deputados; e no caso da saída do governo do Reino Unido do bloco da UE, esse período foi a data do referendo para a saída. Dessa forma, este estudo não analisou se a polarização política diminui com o decorrer do tempo, haja vista que o objetivo deste estudo foi refletir sobre o comportamento político de britânicos e brasileiros em face do processo de criação de sentido e de produção de conhecimento, a partir da análise do conteúdo das manifestações de cidadãos realizadas por meio das hashtags selecionadas na rede social Twitter, nos períodos mais críticos da polarização política relativos aos fenômenos estudados no ano de 2016. 


\section{METODOLOGIA}

Esta pesquisa analisou dois casos em uma ótica comparativa, acerca de aspectos do comportamento dos cidadãos em relação ao uso de mídias sociais digitais ao manifestarem seu posicionamento acerca dos fenômenos marcados por uma polarização política. A escolha pelo impeachament de Dilma Rousseff e pelo Brexit é justificada pela dicotomia na opinião pública nas redes sociais e pela intensidade da movimentação das redes sociais durante os fenômenos, além do fato de que ambos os acontecimentos ocorreram no mesmo ano. Apesar das diferenças entre os países em termos de desenvolvimento econômico, político, social, dimensão terrritorial, entre outros, o estudo comparativo entre esses países se fez relevante devido à repercussão dos fenômenos perante um cenário de iminente crise política. $E$ também pelo fato de os dois casos terem acontecido em 2016. Além disso, ambos os fenômenos desencadearam o contexto político vigente. No contexto brasileiro, a polarização política se intensificou nas eleições de 2018, com a dicotomia esquerdadireita, que culminou na vitória do candidato da direita Jair Bolsonaro. Isso demonstrou o desejo de mudança por parte de alguns cidadãos desde o período do impeachment presidencial. No Reino Unido, o Brexit ainda está em processo, e as incertezas acerca das consequências da saída desse país do bloco europeu ainda reverberam a polarização.

A técnica de pesquisa foi a netnografia dentro da rede social Twitter. A netnografia é uma abordagem metodológica que introduz uma forma especializada de etnografia cuja fonte de dados são as comunicações mediadas por um computador (KOZINETS, 2014). A netnografia, originada nos anos 1990 (FRAGOSO; RECUERO; AMARAL, 2011; POLIVANOV, 2014), relaciona-se à adaptação da etnografia aos meios digitais.

Quanto à coleta de dados, Kozinets (2014) menciona três tipos de coleta "netnográfica": dados arquivais, dados extraídos e dados de notas de campo. Os dados arquivais correspondem a cópias diretas de comunicações mediadas pelo computador, como dados de página - sejam estes sites, blogs ou, no caso desta pesquisa, publicações em uma mídia social digital. Tais dados não podem ter o envolvimento direto do pesquisador, ou seja, o pesquisador não é o criador nem estimulou a criação desses dados (KOZINETS, 2014).

Os demais tipos de coleta denotam a interação do pesquisador com o usuário, por meio de entrevistas, chats virtuais ou até mesmo notas de campo acerca da interatividade entre membros de dada comunidade virtual, possibilitando uma mescla entre a etnografia tradicional e a netnografia (KOZINETS, 2014).

Para a presente pesquisa, a coleta de dados arquivais demonstrou maior adequação, visto que foi realizada uma análise retrospectiva dos fenômenos estudados. Portanto, por meio da abordagem netnográfica, foram selecionadas hashtags entre aquelas que seriam representativas da polarização política. As hashtags selecionadas indicam essa opinião pública dicotômica: no caso brasileiro, foram selecionadas as hashtags \#foradilma, como manifestação favorável ao impeachment, e \#nãovaitergolpe, como opinião contrária; no caso britânico, foram escolhidas as hashtags \#leaveeu, como apoiadora da saída do Reino Unido da UE, e a \#remaineu, do lado oposto. Houve mais hashtags sobre ambos os fenômenos como \#tchauquerida, \#impeachmentday ou \#Brexit ou \#Brexitornot (possível sátira da frase shakespeariana "to be or not to be"), mas que poderiam indicar outros assuntos ou por terem sido citadas por ambos os lados.

A identificação das hashtags foi realizada pelo filtro de busca avançada no Twitter, que permite a seleção por data, localização e idioma. Os dias escolhidas para a busca 
foram 17 e 18 de abril de 2016, com as datas durante e depois da votação da Câmara dos Deputados (17/4/2016), e 23 e 24 de junho de 2016, incluindo o dia que sucedeu ao referendo do Brexit (23/6/2016). Os tweets analisados foram aqueles apontados pela busca como "em destaque" para as hashtags escolhidas no período selecionado. Segundo a central de ajuda do Twitter, a categoria de busca "em destaque" refere-se aos tweets selecionados por meio de um algoritmo, considerando aqueles mais relevantes de acordo com o filtro de busca (TWITTER, 2018). Dessa forma, foram realizadas duas consultas - uma para o dia 17 de abril de 2016, com as hashtags \#foradilma e \#nãovaitergolpe, e outra para o dia 23 de junho de 2016, com as hashtags \#leaveeu e \#remaineu - em que apareceram os tweets tidos como "em destaque" devido à relevância. Essa relevância pode ser medida pela quantidade de visualizações, por popularidade do perfil ou pelo maior número de retweets.

Além disso, dados secundários coletados em outras pesquisas foram considerados na análise, como foi o relatório produzido pelo grupo Social Media and Political Participation (SMaPP) da Universidade de Nova York sobre o fenômeno do Brexit (SIEGEL, 2016). E também trabalhos nacionais sobre a repercussão do impeachment de Dilma Rousseff, a exemplo da investigação feita por Penteado e Guerbali (2016) sobre os perfis de usuários e os posicionamentos e as temáticas das mensagens mais retuítadas nos dias das manifestações pró-impeachment no ano de 2015; e de Malini, Ciarelli e Medeiros (2017), um trabalho relevante que analisou o impeachment de 2016 na rede Twitter.

\section{APRESENTAÇÃO E ANÁLISE DOS RESULTADOS}

Conforme mencionado na seção metodológica, as hashtags escolhidas para análise foram selecionadas entre aquelas que aparecem "em destaque" após a realização da busca avançada no Twitter. A partir dessa consulta, identificou-se um número superior de tweets "em destaque" para o caso do impeachment presidencial brasileiro de 2016, comparativamente aos números do caso do referendo britânico do Brexit, tal como está demonstrado na Tabela 2.

\section{Tabela 2 - Quantidade de tweets "em destaque" analisados nos dias do impeachment presidencial brasileiro e do Brexit em 2016}

\begin{tabular}{l|l|l}
\hline Fenômeno & Hashtags & $\begin{array}{l}\text { Número de } \\
\text { tweets } \\
\text { analisados }\end{array}$ \\
\hline $\begin{array}{l}\text { Impeachment } \\
\text { presidencial }\end{array}$ & \#nãovaitergolpe & 525 \\
$\begin{array}{l}\text { 17/04/2018 } \\
\begin{array}{l}\text { Referendo } \\
\text { do Brexit }\end{array}\end{array}$ & \#foradilma & \\
$23 / 06 / 2018$ & \# remaineu & 58 \\
\hline
\end{tabular}

Fonte: dados da pesquisa.

Essa expressiva diferença entre a quantidade de tweets "em destaque" para os dois fenômenos poderia sinalizar características e peculiaridades do comportamento de brasileiros e britânicos. Observou-se, no caso brasileiro, uma maior incidência de manifestações pessoais. Sem embargo, isso não representa necessariamente maior 
participação política, tanto que os dados da ONU de 2016 envidenciam que os cidadãos do Reino Unido participam mais do que os do Brasil.

Outro fator que permite salientar esse quantitativo superior de tweets "em destaque" do caso brasileiro é a maior incidência de imagens e vídeos em detrimento ao fenômeno britânico: de 525 tweets durante o impeachment presidencial, 188, ou seja, 35,8\% dos tweets em "destaque, continham imagens e vídeos. Excluiu-se dessa apuração os retweets. Já no caso britânico, somente 10 tweets de 58 postados, ou seja, 17,2\%, apresentavam alguma ilustração. Isso evidencia diferenças comportamentais entre cidadãos das duas nacionalidades.

Ao se analisarem, qualitativamente, os tweets "em destaque", apresentados na busca pelo dia 17 de abril de 2016, nota-se que, no caso brasileiro, o uso da mídia social digital pelos cidadãos foi constante e intenso, tanto para posicionamentos a favor quanto contra o impeachment. Para a hashtag \#nãovaitergolpe, contrária ao impeachment, os tweets demonstraram que pessoas que acompanharam o posicionamento do deputado Jean Wyllys, e em relação ao qual se identificavam durante a votação, citaram seu nome em vários tweets. $O$ oposto também ocorreu com aqueles que se posicionaram a favor do impeachment e eram contrários ao voto dado pelo referido deputado, mas mesmo assim o citaram, mas com menor frequência.

Outra pessoa mencionada foi o atual presidente Jair Bolsonaro, outrora deputado em 2016. No entanto, os conteúdos dos tweets estavam vinculados a \#foradilma. Em situação similar ao então deputado citado, houve tweets com menções críticas ao posicionamento de Jair Bolsonaro, relacionando com a \#nãovaitergolpe.

Ressalta-se que os políticos foram os mais citados na data selecionada, o que indica, majoritariamente, uma identificação do posicionamento político do índividuo com a posição desses deputados. Outros políticos também apareceram na busca, mas não estavam relacionados à participação política, e surgiram devido a alguma atitude que tiveram durante a votação na Câmara dos Deputados.

Contudo, também foi observado uma relação entre as hashtags e os twettes com posições contrárias às ideias defendidas pelos deputados, ou seja, as hashtags linkadas não correspondiam aquilo que o político defendia na votação. Isso corrobora os estudos de Barberá (2014), ao concluir que a polarização política não contempla necessariamente o agrupamento de pessoas que compartilham da mesma posição política, podendo haver convivência entre usuários que possuem ideias ambíguas, mesmo que seja com a intenção de produzir humor. Nessa mesma linha, ressalta-se o processo de construção de sentido e produção de conhecimento, em que Nonaka e Takeuchi (1997) destacam o caos criativo.

No caso britânico, a busca avançada no Twitter indicou que o posicionamento político da maioria dos usuários era favorável à saída do Reino Unido da União Europeia, com o maior uso da hashtag \#leaveeu. Também tiveram menções ao ex-primeiro britânico David Cameron, cuja posição estava inclinada à permanência do país no bloco.

Contudo, foram observados tweets que utilizaram a \#leaveeu para criticar o posicionamento majoritário pelo Brexit. Entre as manifestações, houve uma imagem humorística que simbolizava a UE como um guarda-chuva vinculada aos dizeres "Este guarda-chuva não salvará a UE da grande tempestade que virá em seu caminho" (TWITTER, 2016, tradução nossa). ${ }^{2}$ Tal inclinação poderia querer demonstrar o

2 “This umbrela won't save the EU from the big storm coming its way” (TWITTER, 2016). 
sentimento de nacionalismo e o receio dos cidadãos britânicos quanto à segurança, à imigração, etc., mencionados por Bueno (2016). Verificou-se também tweets britânicos em ambas as hashtags para indagar de maneira retórica qual seria o resultado do referendo. A hashtag \#remaineu foi menos utilizada pelos britãnicos, seja para revelar a posição política de usuários ou para mostrar as parciais de enquetes feitas sobre o resultado do referendo do dia 23 de junho de 2016. Não obstante, na pesquisa qualitativa, observam-se manifestações que ressaltam radicalismo político, com teor xenofóbico tal como Bueno (2016) descreveu em seu texto.

O comportamento de britânicos e brasileiros em contextos de polarização política a partir das mídias sociais digitais: principais semelhanças e diferenças

A participação política nas redes sociais comoo Twitter alude à insatisfação dos cidadãos perante seus governos em diversos aspectos. No caso brasileiro, a população estava insatisfeita com as constantes denúncias de corrupção e com a instabilidade política e econômica do país. Já no caso britânico, seus cidadãos estavam contrários ao estado de insegurança devido ao medo de ameças de terrorismo, e visavam um maior controle do fluxo de imigrantes.

Os aspectos do comportamento dos cidadãos relativos ao seu posicionamento nos casos brasileiro e britânico de polarização política do ano de 2016 foram marcados tanto por similitudes como por diferenças, apesar das diferenças serem mais evidentes. Esse fato pode ser justificado possivelmente por diferenças culturais ou talvez pelo nível de maturidade dos diferentes cidadãos em relação à sua consciência política ou à sua percepção sobre o papel que desempenha na sociedade. O Quadro 1 apresenta o comparativo entre semelhanças e distinções nos dois casos.

Quadro 1 - Semelhanças e diferenças no posicionamento dos cidadãos no Twitter perante os casos brasileiro e britânico de polarização política no ano de 2016

\begin{tabular}{|c|c|c|}
\hline SEMELHANÇAS & DIFERENÇAS & \\
\hline $\begin{array}{l}\text { Presença de dicotomia de } \\
\text { posicionamentos }\end{array}$ & BRASIL (Impeachment) & REINO UNIDO (Brexit) \\
\hline $\begin{array}{l}\text { Criação de perfis na rede } \\
\text { social Twitter } \\
\text { representassem que } \\
\text { posicionamento de cada lado } \\
\text { (favor ou contra o fenômeno } \\
\text { político) }\end{array}$ & $\begin{array}{l}\text { O posicionamento dos } \\
\text { cidadãos se identificava } \\
\text { com a posição dos } \\
\text { políticos. } \\
\text { Posicionamento } \\
\text { ideológico esquerda- } \\
\text { direita. }\end{array}$ & $\begin{array}{l}\text { Os posicionamentos dos } \\
\text { cidadãos demonstrou } \\
\text { preocupação com as } \\
\text { consequências, os } \\
\text { resultados, desse } \\
\text { fenômeno. } \\
\text { Pouca identificação com } \\
\text { atores políticos. }\end{array}$ \\
\hline Produção de humor & $\begin{array}{l}\text { Usuários } \\
\text { essencialmente } \\
\text { brasileiros }\end{array}$ & $\begin{array}{l}\text { Houve manifestações de } \\
\text { usuários de outras } \\
\text { nacionalidades, além da }\end{array}$ \\
\hline
\end{tabular}




\begin{tabular}{|c|c|c|c|}
\hline & & & britânica \\
\hline $\begin{array}{l}\text { Presença de radicalismo } \\
\text { político, em menor grau }\end{array}$ & $\begin{array}{l}\text { Polarização } \\
\text { (\#foradilma } \\
\text { \#ficadilma). }\end{array}$ & $\begin{array}{r}\text { acentuada } \\
\text { e }\end{array}$ & $\begin{array}{l}\text { Predomínio da hashtag } \\
\text { \#leaveeu, a favor do } \\
\text { Brexit. }\end{array}$ \\
\hline
\end{tabular}

Fonte: dados da pesquisa.

Com relação às semelhanças, além de ambos os casos serem marcados por uma dicotomia de posicionamentos, com menor frequência de neutralidade, nos dois fenômenos políticos houve a criação de perfis na rede social Twitter que evidenciassem uma posição política, embora tenha sido mais frequente no caso brasileiro. Nessa situação, o cidadão está sob anonimato, apenas demonstrando seu posicionamento. Também em ambos os casos, observou-se a retratação dos fenômenos de polarização política por meio do humor.

As diferenças entre os comportamentos dos cidadãos em suas manifestações no Twitter sobre fenômenos do impeachment da presidenta Dilma Rousseff e do Brexit detectam distinções quanto aos posicionamentos. Enquanto no caso brasileiro os posicionamentos dos cidadãos refletiam a sua posição ideológica no cenário político de polaridade, mediante a identificação com os posicionamentos de determinados atores políticos (os deputados federais), no caso britânico os posicionamentos demonstraram uma preocupação com o resultado desse referendo e suas possíveis consequências. Tais consequências podem impactar questões importantes na agenda política do Reino Unido, como a economia, a migração, a segurança, entre outras.

Outra distinção entre os casos analisados foi a nacionalidade dos usuários na rede social Twitter durante as manifestações dos fenômenos políticos. Na pesquisa, foram selecionados os países Brasil e Reino Unido no filtro de busca avançada no Twitter, onde ocorreram os respectivos fenômenos de polarização política, porém se notou que os cidadãos brasileiros compunham massivamente os posicionamentos sobre o impeachment, já no Reino Unido foram detectados cidadãos de outras nacionalidades. Isso é justificado pela repercussão do Brexit, que pode influenciar questões como a permanência e a entrada de imigrantes no Reino Unido.

\section{CONCLUSÕES}

As manifestações da polarização política nas mídias sociais digitais apontam para um dilema: se estas são um canal de interação ou se se configuram como um meio unilateral de comunicação entre os atores de um mesmo grupo. Penteado e Guerbali (2015) afirmam que o formato das redes sociais como o Twitter se fecha em perfis com comportamentos similares, com a formação de nichos. Isso restringe o contato entre os indivíduos, pois somente interagiriam aqueles com pensamentos semelhantes. Todavia, o resultado da pesquisa evidenciou o oposto. Mesmo com posições políticas distintas, as interações ocorrem, principalmente para produzir humor, fato que corrobora o argumento de Barberá (2014).

O posicionamento político dos cidadãos em espaços interativos, como as redes sociais, dinamiza o debate e as reflexões sobre os problemas governamentais ao possibilitar maior liberdade de expressão. Tanto na experiência do impeachment no 
Brasil, como na saída do Reino Unido da UE, houve a articulação entre usuários com posicionamentos diferentes. Apesar de cada lado reafirmar suas ideias, a diversidade de opiniões contribuiu para o processo democrático. Esse contexto se alinha, pois, às premissas do sensemaking e da produção de conhecimento, conforme os estudos de Weick (1995), Nonaka e Takeuchi (1997) e Choo (2003).

Com a premissa da interligação dos processos de criação de sentido, produção de conhecimento e tomada de decisão, observa-se que as mídias sociais digitais possibilitaram a ampliação das arenas de debates, o que levou a contextos de intensas ressignificações de ideias estabelecidas, a partir de situações de ambiguidades inerentes a mudanças e transformações próprias do caos criativo. A produção de conhecimento se faz nesses espaços comunicativos, que integram atores diversos, mesmo com posicionamentos polarizados, desencadeando ações e decisões dentro de um processo contínuo. Pela intensificação do uso das mídias sociais digitais, cresce a expectativa de que as essas interações sejam apropriadas cada vez mais pelo governo e pelos cidadãos. Tanto no Brasil quanto no Reino Unido, o uso das mídias digitais vem ampliando seu protagonismo. No Brasil, o atual governo já demonstra o uso intensivo das mídias sociais e, no caso do Brexit, o impasse permanece com a derrota do acordo de saída do Reino Unido da UE em 15 de janeiro de 2019 (BARNES, 2019). Assim, no continuum de futuros estudos, sugere-se, pois, o acompanhamento do desenrolar dessas dinâmicas a partir das mídias sociais digitais e de seus efeitos na produção do conhecimento coletivo.

Artigo recebido em 31/01/2019 e aprovado em 15/05/2019.

\section{REFERÊNCIAS}

AMARAL, A. Autonetnografia e inserção online: o papel do pesquisador-insider nas práticas comunicacionais das subculturas da web. Revista Fronteiras: estudos midiáticos, v. 11, n. 1, p. 14-24, jan./abr. 2009.

ARAÚJO, R. M. et al. Governo eletrônico: um estudo sobre as possibilidades de participação do cidadão. Informação \& Sociedade: estudos, João Pessoa, v. 23, n.1, p. 73-90, jan./abr. 2013.

BARBERÁ, P. How social media reduces mass political polarization: evidence from Germany, Spain, and the US. Job Market Paper, Nova York: New York University, v. 46, 2014.

BARNES, P. Brexit: o que ocorre agora que o Parlamento britânico rejeitou o acordo de Theresa May? BBC News Brasil, 15 jan. 2019. Disponível em: <https://www.bbc.com/portuguese/internacional-46881488>. Acesso em: 16 jan. 2019.

BRAGA, A. Técnica etnográfica aplicada à comunicação online: uma discussão metodológica. UNIRevista, v. 1, n. 3, jul. 2006.

BUENO, C. Brexit e o novo momento para a Europa. Ciencia e Cultura, v.68, n. 4, p.1416, dez. 2016.

CHOO, C. W. A organização do conhecimento. São Paulo: Senac, 2003.

CORREAA, M. V.; ROZADOS, H. B. F. A netnografia como método de pesquisa em Ciência da Informação. Encontros Bibli: revista eletrônica de biblioteconomia e ciência da informação, v. 22, n. 49, p. 1-18, 2017. 
DACOS, M. Manifesto delle digital humanities. THATCamp, 26 mar. 2011.

FARRANHA, A. C. et al. Mídias sociais digitais e administração pública: o caso do Ministério do Desenvolvimento Social (MDS) e da Secretaria Especial de Políticas para as Mulheres (SPM). RP3: revista de pesquisa em políticas públicas, v. 1, n. 2, 2015.

FRAGOSO, S.; RECUERO, R.; AMARAL, A. Métodos de pesquisa para internet. Porto Alegre: Sulina, 2011.

GOMES, W et al. "Politics 2.0": a campanha online de Barack Obama em 2008. Revista de Sociologia e Política, Curitiba, v. 17, n. 34, p. 29-43, out. 2009.

. Democracia digital: que democracia. In: MIGUEL, Luis Felipe; BIROLI, Flávia (Org.). Mídia, representação e democracia. São Paulo: Hucitec, 2010.

KOZINETS, R. V. Netnografia: realizando pesquisa etnográfica online. Porto Alegre: Penso, 2014.

MALINI, F.; CIARELLI, P.; MEDEIROS, J. O sentimento político em redes sociais: big data, algoritmos e as emoções no tweets sobre o impeachment de Dilma Rousseff. Liinc em Revista, Rio de Janeiro, v. 13, n. 2, p. 323-342, nov. 2017.

NOIRET, S. História pública digital. Liinc em Revista, v. 11, n. 1, p.28-51, 2015.

NONAKA, I.; TAKEUCHI, H. Criação de conhecimento na empresa: como as empresas japonesas geram a dinâmica da inovação. Rio de Janeiro: Campus, 1997.

OLIVEIRA, D. J. S.; BERMEJO, P. H. S. Mídias sociais e administração pública: análise do sentimento social perante a atuação do governo federal brasileiro. Organizações \& Sociedade, v. 24, n. 82, 2017.

ONU. United Nations e-government survey 2016: e-government in support of sustainable development. Nova York: ONU, 2016. Disponível em: <http://workspace.unpan.org/sites/Internet/Documents/UNPAN97453.pdf >. Acesso em: $1^{\circ}$ maio 2018.

PENTEADO, C. L. C.; GUERBALI, J. G. As manifestações do impeachment no Twitter: uma análise sobre as manifestações de 2015. Ponto-e-Vírgula: revista de ciências sociais, n. 19, 2016.

PINHO, J. A. G. de; IGLESIAS, D. M.; SOUZA, A. C. P. Governo eletrônico, transparência, accountability e participação: o que portais de governos estaduais no Brasil mostram. In: ENCONTRO NACIONAL DA ASSOCIAÇÃO NACIONAL DE PÓSGRADUAÇÃO E PESQUISA EM ADMINISTRAÇÃO, 29., 2005, Brasília. Anais... Brasília: Anpad, 2005.

POLIVANOV, B. B. Etnografia virtual, netnografia ou apenas etnografia? Implicações dos conceitos. Esferas, v. 1, n. 3, 2014.

SIEGEL, A. Brexit' data report. Nova York: Social Media and Political Participation Lab, New York University, 2016. (SMaPP Data Reports). Disponível em: <https://wp.nyu.edu/smapp/wpcontent/uploads/sites/1693/2016/01/SMaPP_Data_Report_2016_03_Brexit.pdf >. Acesso em: 10 maio 2018.

SPINELLI, R. Q. O poder em ação: um estudo sobre os comportamentos políticos no contexto organizacional. 2010. Dissertação (Mestrado em Administração) - Escola Brasileira de Administração Pública e de Empresas, Fundação Getúlio Vargas, Rio de Janeiro, 2010 
TWITTER. Busca avançada por: \#leaveeu OR \#remaineu since:2016-06-23 until:201606-24 em 10 maio 2018.

Busca avançada por: \#foradilma OR \#nãovaitergolpe since:2016-04-17 until:2016-04-18 em 10 maio 2018.

O que são tweets "em destaque"? Disponível em: <https://help.twitter.com/pt/using-twitter/top-search-results-faqs>.Acesso em: 10 maio 2018.

WEICK, K. E. Sensemaking in organizations. London: Sage, 1995. 